\title{
ONLINE PURCHASE PREFERENCE AND PERSONAL CHARACTERISTICS: A MODERATION APPROACH
}

\author{
Zhen $\mathrm{Li}$ \\ Toyo University \\ 5-28-20 Hakusan, Bunkyo-Ku, Tokyo 112-8606, Japan. \\ li@toyo.jp \\ Avus CY. Hou* \\ Oriental Institute of Technology \\ 58-2 Sichuan Rd., Banqiao Dist., New Taipei City 220, Taiwan. \\ avushou@mail.oit.edu.tw \\ ${ }^{*}$ Corresponding author
}

\begin{abstract}
This study posits that personal characteristics affect behavioral outcomes through directly influencing purchase preference and moderating preference effects of other factors. To further clarify this mechanism, we perform a longitudinal survey to investigate the direct effects of personal characteristics on online purchase preference and the moderating effects of these characteristics on the influences of two online purchase goals (saving money and saving time) on purchase outcomes. Customers' personal characteristics in this study mainly include gender, income, age, education, work status, and experience of online shopping. The results show that only age and online experience have direct effects on online purchase preference. By contrast, an important finding suggests that most of those personal characteristics affect purchase outcomes mainly through moderating the preference effects of the two online purchase goals, rather than directly influencing purchase preferences. Management implications and future research directions are also presented at the end of the paper.
\end{abstract}

Keywords: Online Purchase Preference, Personal Characteristics, Moderation Approach, Moderating Effect

\section{INTRODUCTION}

During the last decade, more than $60 \%$ of the 2.8 billion Internet users shopped through the Internet, making online shopping more and more popular ${ }^{1}$. Reports from Statista $^{2}$ and China Electronic Commerce Research Center ${ }^{3}$ declare that in 2017, there were nearly 200 million online shoppers in the United States and the number in China topped 530 million. The increasing number of online shoppers implies that it is crucial for online retailers to understand consumers' purchase preferences.

Prior research indicates that the factors of personal characteristics of shoppers affect customer patronage preference, and thus give shop managers the insight needed to target consumers ${ }^{4}$. In this study, therefore, we focus on the relationship between customers' personal characteristics and their purchase preferences for online and 
in-shop purchases. The topic of what types of consumers are more likely to make online purchases have received widespread attention in retailing literature ${ }^{3,4}$. Many studies have documented that, compared with non-Internet shoppers, online shoppers tend to be younger, better-educated, wealthier, and more computer literate, but are also more time-constrained ${ }^{5,6}$. Although there is extensive evidence that personal characteristics (i.e., gender, income, age, education, work status, the experience of online shopping) have strong effects on consumers purchase preference, most studies only focused on the differences in the descriptive statistical distribution of survey results of purchase preference among different characteristics of participants. In other words, little is known about how the afore-mentioned characteristics affect the purchase outcomes and how the effects take place. In addition, it is unclear through what mechanism the influence of the personal characteristics purchasing behavior, if at all.

Literature in consumer behavior and e-retailing domains has suggested that saving money and saving time are two of the most important goals of online purchasing $7,8,9$. In addition, prior research has proposed that money consciousness and time consciousness vary with changing personal characteristics ${ }^{10,11}$. Building on this idea, this paper speculates that customers' personal characteristics partially affect purchase preferences for online and offline shopping by moderating the influences of saving money and saving time on purchase outcomes. As for this approach, the effects of cost- and time-efficiency on the purchase decision process are well established ${ }^{7,8}$, ${ }^{12}$. In addition, despite there only being a small number of studies on the relationship between personal characteristics and money and time consciousness, Punj ${ }^{9}$ has confirmed the effects of income on saving money and saving time as two online purchase goals and discussed the differences in these income effects across other socioeconomic characteristics. On the basis of Punj's research, this study attempts to extend the moderating effect into other personal characteristics.

The objectives of this study are twofold: (1) to examine the relationship between purchase preference and personal characteristics, and (2) to clarify the influence paths of customers' personal characteristics on purchase preference if any. To study the underlying mechanism of how personal characteristics influence online purchase performance, this study proposes a logit moderation model to investigate (1) the direct effects of personal characteristics on the likelihood of online patronage preference and (2) the moderating effects of personal characteristics on the influence of two online shopping goals (i.e., saving money and saving time) on purchase outcomes on the basis of the methods used by Punj ${ }^{9}$. Customers' personal characteristics in the present study include gender, income, age, education, work status, and experience of online shopping. The data are generated through an online survey in three of the world's largest online markets with different cultures and economic policies: the United States, Japan, and China. Based on the analysis, we find that personal characteristics affect purchase outcomes mainly through their moderating effects on consumers' money consciousness and time consciousness in online shopping, respectively, rather than directly influencing the purchase preference itself.

The present study provides valuable insights not only for academics but also for online retailers. The major contribution of this study is to provide a moderation approach to better explicate the effects of personal characteristics on online purchase preference and further clarify the influence paths of personal characteristics on online purchase preference. This can help retailers to better understand the difference in purchase preference across market segments, and the fundamental reasons for this 
difference. In addition, this research assists managers to take effective steps to improve the likelihood of customer purchase.

The rest of the study is organized as follows. Section 2 introduces the theoretical foundation for the moderation mode and features a review of the literature that grounds the key hypotheses. Section 3 reports the data collection practice and includes descriptive statistics on the collected data. Section 4 presents the econometric analyses and explicates the key findings that can be generated from the analysis. Finally, we offer conclusions and describe the implications in Section 5.

\section{THEORY AND REVIEWS}

Sheth $^{2}$ identifies that customer purchase preference is influenced by the personal characteristics of shoppers, including demographics and lifestyles. Although Sheth's study primarily focuses on consumer behavior in traditional markets, the conclusions are applicable to online shopping behavior as well ${ }^{13,6}$. There is substantial interest in the relationship between online purchase preference and personal characteristics, however, prior research seldom discusses through what mechanism personal characteristics influence purchase preference. $\mathrm{Punj}^{9}$ pointed out that income level significantly relates to saving money and saving time as two online purchase goals, but the literature still lacks an empirical study that confirms whether this finding applies to other consumer characteristic factors. Building on this idea, this study posits that personal characteristics influence purchase preference in two ways: (1) the direct way and (2) the indirect way through moderating the impact of the above two goals (i.e., saving money and saving time) on purchase preference. In this section, we first outline the theory of the moderation model, followed by reviews of the relationships among the antecedent factors mentioned in the literature: personal characteristics, purchase preference and the two online goals.

\subsection{Moderation Model}

In this subsection, we focus on the theory of the moderation model. Moderation analysis tests the role of a third variable in adjusting the effects of other independent variables on dependent variables. In statistical methodology, moderation occurs when the relationship between two variables depends on a third variable, which is referred to as the moderator ${ }^{14}$. In general, the moderator is a categorical or quantitative variable that affects the direction or strength of the relationship between dependent and independent variables.

Figure 1 shows a simple moderation model with an independent variable $(\mathrm{X})$, a dependent variable (Y), and a moderator (M). In this figure, $a$ indicates the effect of independent variable $\mathrm{X}$ on dependent variable $\mathrm{Y} ; b$ represents the moderating effect of moderator $\mathrm{M}$ on the effect $a$, and $c$ represents the direct effect of $\mathrm{M}$ on $\mathrm{Y}$ after considering the moderation effect $b$. That is to say, $a+b$ denotes the moderated effect of $\mathrm{X}$ on $\mathrm{Y}$ through $\mathrm{M}$. In this case, the moderating effect of $\mathrm{M}$ on the influence of $\mathrm{X}$ on $\mathrm{Y}$ can be confirmed if both $a$ and $b$ are significant. In addition, the effect of $\mathrm{M}$ on $\mathrm{Y}$ is completely determined by its moderating effect if $a$ and $b$ are significant but $c$ is not, while it includes both direct effect and moderating effect if all of $a, b$, and $c$ are significant. Figure 2 intuitively displays the meanings of $a, b$, and $c$ in the aforementioned moderation model. Given the property of moderator we mentioned above, $\mathrm{M}$ is simply assumed as a binary variable with the value of 0 or 1 in this figure; and $E(\mathrm{Y} \mid \mathrm{X}, \mathrm{M})$ represents the relationship of $\mathrm{Y}$ with $\mathrm{X}$ and $\mathrm{M}$. Within a correlational 
analysis framework, the moderator affects the value of the slope of the dependent variable on the independent variable ${ }^{15}$. Therefore, as Figure 2 shows, the moderating effect of $\mathrm{M}$ on the influence of $\mathrm{X}$ on $\mathrm{Y}$ (i.e., $b$ ) is represented by the difference in slopes between the functions of $E(\mathrm{Y} \mid \mathrm{X}, \mathrm{M}=1)$ and $E(\mathrm{Y} \mid \mathrm{X}, \mathrm{M}=0)$, and the direct effect of $\mathrm{M}$ on $\mathrm{Y}$ (i.e., $c$ ) is indicated by the difference in their intercepts.

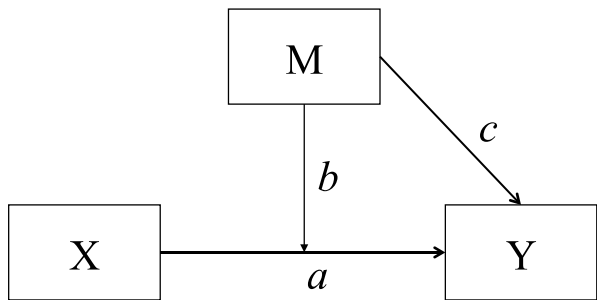

Figure 1. Moderation Model (1)

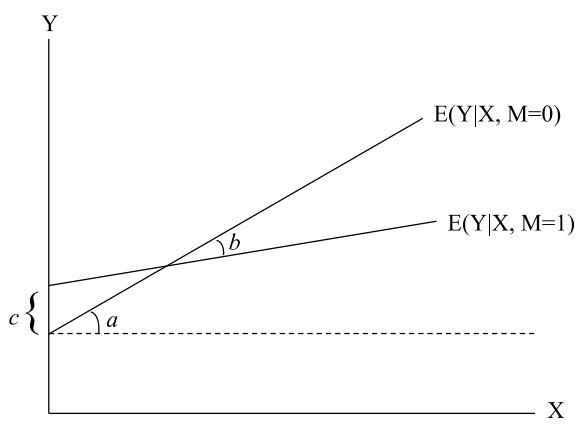

Figure 2. Moderation Model (2)

Substantial evidence has suggested that saving money and saving time are two of the most important goals of online purchasing, which are significantly related to customer purchase preferences for online shopping. In addition, building on the idea of Punj ${ }^{9}$, personal characteristics of online shoppers are speculated to moderate the effects of the two goals on online purchase preference. Therefore, in this case, the independent variables are saving money and saving time as two online purchase goals, and the dependent variable is consumers' purchase preference. In addition, personal characteristics in this study are regarded as the moderator to adjust the effects of costand time-efficiency on purchasing decision-making. To explore through what mechanism customers characteristics influence their purchase preference, we therefore assume that personal characteristics of online shoppers will affect online purchase preference through both their direct effects and their moderating effects on the relationship between purchase preference and the two objectives most consumers identify as reasons for shopping online, namely, saving money and saving time.

\subsection{Reviews and Hypotheses}

On the basis of the above moderation model, this subsection reviews the literature related to the relationship between personal characteristics, purchase preference, and the two online goals of saving money and time. Following prior research, we focus on the personal characteristics of consumers' demographics and lifestyles. Empirical hypotheses are proposed in this subsection.

\subsubsection{Demographics}

Gender has been largely discussed as an important factor to explain online shopping behavior ${ }^{16,17,18}$. Unlike traditional in-store shopping, which is performed by females, a number of studies have identified that males are more likely to make a purchase decision online ${ }^{19,20}$. Comber et al. ${ }^{21}$ demonstrated that males, rather than females, have greater experience with and more positive attitudes toward computers and the Internet. Garbarino and Strahilevitz ${ }^{16}$ found that women perceive a higher level of risk in online purchasing than men. Li and Huang ${ }^{22}$ suggested that males are inclined to make an online purchase decision because of time consciousness. These findings also indicate that while men may make purchases out of need, women have an innate love for shopping that incites them to ignore the time they spend engaged in 
online shopping. Some other empirical studies also indicated that men value time more than women do because men are results-oriented ${ }^{23,24}$. In addition, a survey reported by the Ministry of Economy, Trade, and Industry (METI) in Japan showed that the importance of cost saving is stronger in males than in females, while females pay more attention to service and satisfaction. Therefore, the hypotheses related to the gender difference in online purchase are offered as follows:

H1a: Compared with females, males have a greater purchase preference for online shopping.

$\mathrm{H} 1 \mathrm{~b}$ : The effects of saving money and saving time on online purchase preference are more pronounced for men than for women.

In consumer behavior theory and economic theory, income is always regarded as an important factor to predict consumer demand ${ }^{25}$. Despite online shopping being more economical than offline shopping ${ }^{26}$, some studies, like Bellman ${ }^{27}$ and Swinyard and $\mathrm{Smith}^{6}$, found Internet shoppers to be wealthier. In addition to this direct impact, the income also moderates the valuations of cost and time due to differences in opportunity $\operatorname{cost}^{28}$. Besides this, Punj ${ }^{9}$ found that income positively affects a customer's preference to save time in purchasing activities but negatively relates to the preference to save money. The finding means high-income consumers preferred time, while the low-income group values money. Li and Huang ${ }^{22}$ stated that the effect of delivery time on patronage preference for the Internet is positively moderated by income level, though the difference in the effect of time saved is weak. One possible economic explanation attributes this to the law of the diminishing marginal rate of substitution that drives higher-income consumers to have more interest in the time-saving characteristics of online shopping, while lower-income consumers tend to have more interested in saving money. Therefore, a rise in income level could increase the likelihood of patronage preference for the Internet, and moderate the impacts of saving money and saving time on online purchases, leading to the following hypotheses:

H2a: Income level has a positive direct effect on online purchase preference.

$\mathrm{H} 2 \mathrm{~b}$ : A rise in income level intensifies the effect of saving time on online purchase preference, but weakens the effect of saving money.

Young people are more likely to make online purchases ${ }^{27}$. Young people use e-commerce much earlier, spend more time surfing the Internet, and prefer to obtain information from the Internet ${ }^{29}$. In addition, young consumers trust e-commerce more than seniors ${ }^{30,31}$. On the other hand, because of the important generational differences in the use of the Internet, age potentially moderates the effect of mental accounts on online purchase goals (i.e., saving money and saving time) of interest ${ }^{9}$. On the basis of Punj's study, Li and Huang ${ }^{22}$ demonstrated that time consciousness in online shopping is more pronounced for consumers who are relatively young. Hence, the hypotheses related to income are stated as follows:

H3a: Younger customers tend to shop online more than older customers.

H3b: Young consumers exhibit a greater tendency toward saving money and time, which indirectly leads to their dominant position in online shopping.

Similar to gender and age, Internet shoppers tend to be better educated ${ }^{27,6}$. 
Related studies demonstrated that more educated consumers are more capable of processing information in their shopping activities ${ }^{32,33}$. Besides, as has been reviewed by Punj ${ }^{9}$, consumers with better education seem to be more likely to engage in an extended search for information and make greater use of price information ${ }^{34,35}$. In addition to these reasons, education level also has a significant correlation with income ${ }^{36,37}$. Hence, it can be considered that education may affect customer patronage preference, and also moderate consciousness with respect to saving money and saving time in online shopping, which leads to the following two hypotheses:

H4a: Education level is positively related to online consumer purchase preference.

H4b: Education level intensifies the effects of saving money and saving time on online purchase preference.

\subsubsection{Lifestyle}

Internet usage is considered the most important factor to predict consumer patronage intentions for the Internet and local stores ${ }^{4}$. In the literature, typical Internet shoppers experience a more "wired lifestyle" and are more time-constrained than those who have less experience of online shopping ${ }^{5,6}$. According to Moe and Fader ${ }^{38}$, a "wired lifestyle" is regarded as a critical predictor of consumer perceptions of risk related to online shopping, characterizing consumers who frequently and expertly use the Internet. On the other hand, in addition to the finding that acquired experience with online shopping nullifies the influence of socioeconomic characteristics ${ }^{3}$, the experience of online purchases is positively related to online shopping tendency and negatively related to the likelihood to abort an online transaction ${ }^{39,40}$. This means that shoppers who have extensive online experience are more likely to make an online purchase decision because such consumers have a relatively high ability to process information from the Internet. Furthermore, their experience helps consumers to reduce their perception of risk associated with e-commerce ${ }^{41}$. Similarly, Li and Huang $^{22}$ found that having engaged in online shopping can attenuate consumer perceptions of risk related to delivery time. Therefore, the hypotheses related to the relationship between online purchase experience and patronage preference are offered as follows:

H5a: Experience of online shopping has a positive direct effect on consumer online purchase preference.

H5b: Experience of online shopping reduces the level of perceived risk in delivery time, improving the likelihood of online purchase.

Time constraints are rooted in the negative effect of learning about products in physical stores. Hence, time-starved people, as well as those living a wired lifestyle, are more likely to make an online purchase ${ }^{27}$. Additionally, consumers who have more time and less income exhibit a greater tendency toward saving money by purchasing online, while those who are "income richer and time poorer" show interest in saving time ${ }^{9}$. The economic theory stipulates that consumers will balance time-related costs on the basis of the economic value they place on that time ${ }^{9,26,42}$, which indicates that time-starved people tend to value their time more than those with extensive time resources. Thus, hypotheses are proposed as follows:

H6a: Time-starved consumers are more likely to shop online than those who have more discretionary time. 
H6b: Discretionary time availability relates positively to saving money as an online purchase goal, while negatively to saving time.

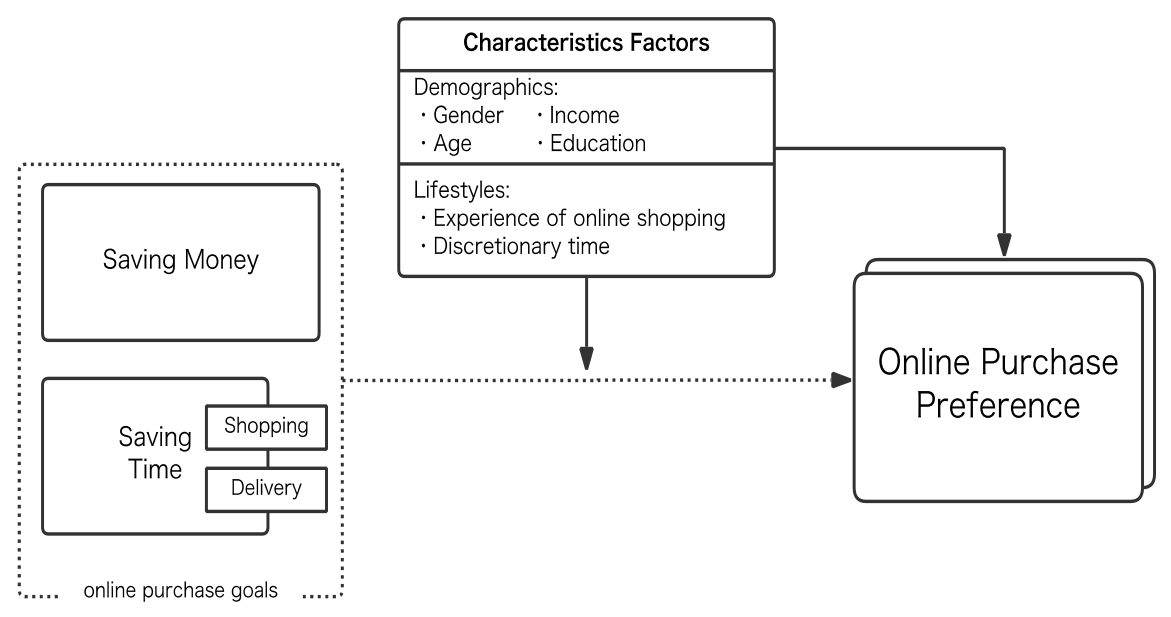

Figure 3. Research model

Figure 3 summarizes the framework for the research hypotheses in this section through a visual representation.

\section{DATA COLLECTION}

In this section, we gather data to carry out the moderation analysis and to test the above hypotheses. The data were collected through a longitudinal anonymous Online survey, which was administered in the United States, Japan, and China from April 2010 to May 2013 by Google form and Sojump.com (since Google forms cannot be accessed in China, we used Sojump.com instead). The survey contains 13 items in total. Among them, 6 items related to the respondents' demographics, 1 item relates to their experience of online shopping, and the rest relate to other matters. The respondents were required to respond with their purchase preference, based on a given product's purchase information, which includes the costs in money and time on both the Internet and in physical stores. The product is randomly selected from a category of clothing because the sales volume of this category is high in both traditional and Internet markets. In this survey, the costs in money and time are utilized by using stated preference data instead of revealed preference data because the latter is typically inaccessible ${ }^{43}$. Stated preference data relates to stated intention preference and is typically considered to be opposite to revealed preference data. The contents of the questionnaire were the same in both two platforms.

The 6 items related to demographics include gender, age, education, income level, work status, and respondents' nationality. In this part, the item of "gender" was measured as a nominal scale $(1=$ Male, $2=$ Female), as well as the item of "nationality" ( $1=$ China, 2 = Japan, 3 =USA), "age" was measured on a 5-point scale ( $1=$ Under 20, $2=20 \sim 29,3=30 \sim 39,4=40 \sim 49,5=$ Over 50), and "education" was measured on a 3 -point scale ( $1=$ Under high school; $2=$ College, $3=$ Graduate $)$. The item of "income level", which asks the respondents' about their personal average annual income, was measured on 6-point scale $(1=$ Less than $\$ 5,000$ to $6=$ More than $\$ 80,000)$, and the item of "work status", which asks how many days a respondent 
works in a week, was measured on a 3 -point scale ( $1=$ Less than 3 days, $2=3$ days to 4 days, $3=5$ days or above). The item related to lifestyle asks about previous experience concerning online shopping, denoting the frequency with which the respondent engages in online shopping per month. Similarly, a 3-point scale $(1=$ Less than 3 times, $2=3$ times to 9 times, $3=10$ times or above) was used to measure the lifestyle item.

We strengthen the validity of our findings by collecting the data in two stages. To avoid the multiple submissions, we limited the participants' user ID and IP address that only one response can be submitted. In addition, based on the method by related research $^{13}$, responses with missing answers or generated in less than 15 seconds were considered as invalid. In our study, the average response time in this study is 42.7 seconds, 0.1 quantile is 14.7 seconds, and 0.5 quantile is 53.4 seconds. Table 1 outlines the description of the sample information. The initial sample was obtained in October 2012. A total of 2,348 people participated in the survey, and 1,595 valid respondents were collected $(67.9 \%$ efficient). The responses comprised of 789 (49.47\%) respondents for "purchase online," 524 (32.85\%) respondents for "purchase in-shop," and $282(17.68 \%)$ respondents for "either."

The first stage sample is comprised of 904 males (56.7\%) and 691 females (43.3\%). As shown in Table 1, the percentage of males in the online purchase group skews slightly higher than it does in the in-shop purchase group. The respondents in the online purchase group are predominately aged between 20 and 40, while those who chose in-shop purchase are mainly aged over 30 . This distribution of age is consistent with the literature ${ }^{3,31,40}$. For the distributions of education and income, the ratio variations between the two groups (i.e., online and in-shop) are less marked. The majority of the respondents have a college degree or above and earn an annual income of $\$ 15,000$ to $\$ 50,000$. However, due to the income differences between countries, we note that the modal category for income was $\$ 5,000$ to $\$ 30,000$ annually in China, while it is $\$ 30,000$ and $\$ 80,000$ annually in Japan and the United States. The status of employment demonstrates that $52.8 \%$ of the participants in this stage work five days or more per week. Nonetheless, it is also shown that the respondents who chose purchase online are more time-constrained than those who chose purchase in-shop from the relative proportions. Approximately $52.7 \%$ of the respondents purchase online equal to or more than 3 times per month. More, $38.8 \%$ of them purchase more than 10 times per month. By contrast, the percentages of online shopping experience for the in-shop group are $43.7 \%$ and $15.5 \%$, respectively.

The second stage includes responses from up to March 2013. Of the 2,779 responses returned, 2,094 (75.4\%) are valid. Among them, 1,072 (51.2\%) respondents chose online purchase, $545(26.0 \%)$ of respondents chose in-shop purchase, and 477 $(22.8 \%)$ of respondents chose either. In the second stage, the ratios of males $(51.2 \%)$ and females $(48.8 \%)$ are nearly evenly split. However, the proportion of males in the online purchase group seems to be somewhat higher, as is also the case for the results in the first stage. The modal category for age in the online purchase group is the 20s, while in the in-shop group it is 40s. Similar to the summary in the first stage, most of the respondents have received college education or higher and work five days or more in a week. The modal income category is $\$ 15,000$ to $\$ 30,000$ for the all respondents, while it is $\$ 5,000$ to $\$ 15,000$ in China. Compared with the participants that prefer shopping at physical stores, the respondents in the online purchase group seem to have more experience with online shopping. 
We check for sample bias by contrasting the sample distribution in the two stages and by comparing the consistency between the sample in this study and those used in extant studies ${ }^{9,13}$. Through the comparison, we find that the sample distribution in the two stages aligns fairly well and closely matches the samples used in the literature and survey reports in terms of demographics and regional characteristics. Thus, in this study, we decide to use the entire data set collected in both of the two stages. To clarify the relationship between personal characteristics and patronage preference, we focus on the sample of 2,930 respondents who did not choose "either." In the following section, we describe the processes of moderation analysis and report the results.

Table 1. Description of the sample information

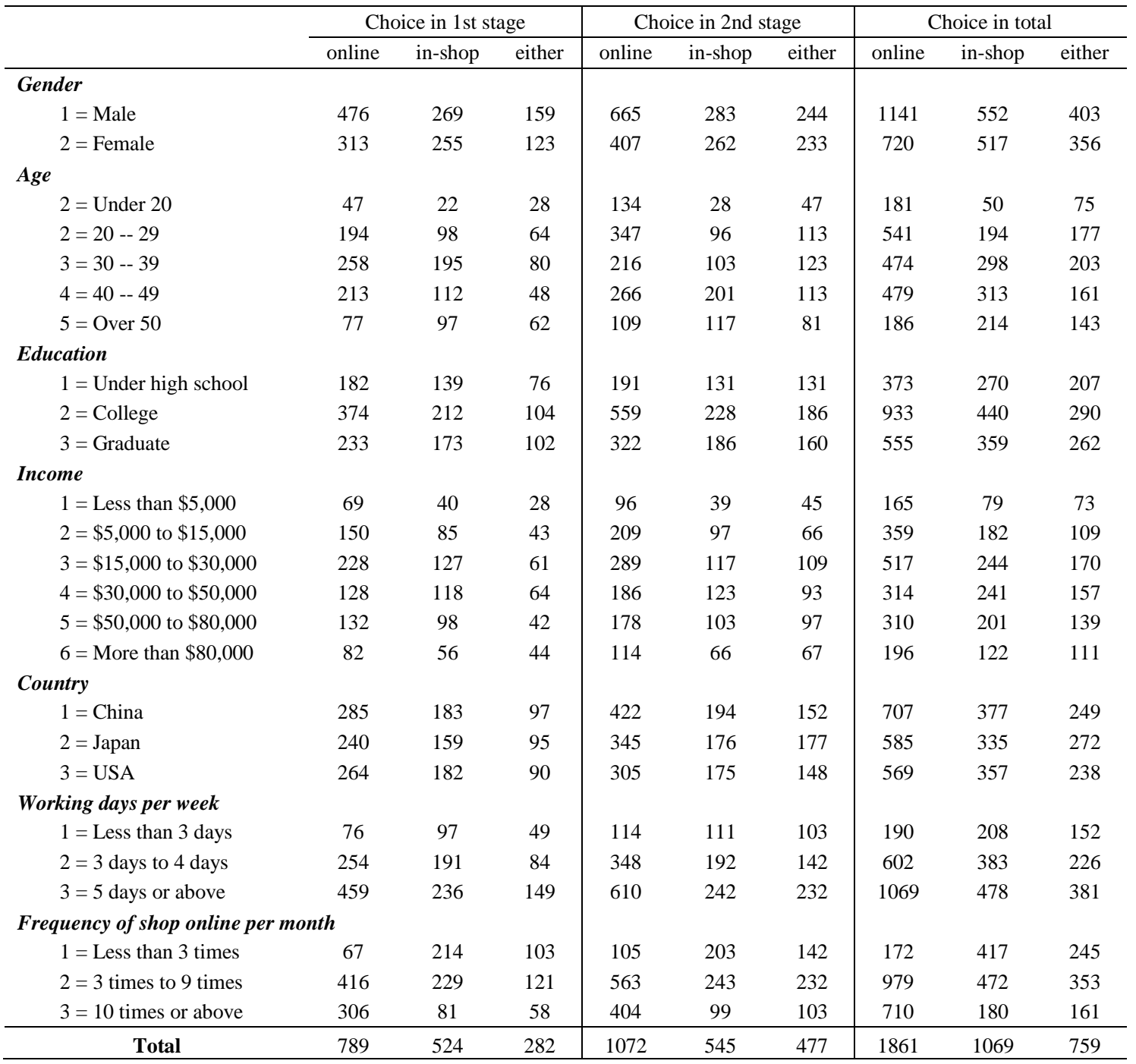

\section{MODERATION ANALYSIS}

In this section, we first provide a contingency table analysis to verify the relationship between personal characteristics and online purchase preference, followed by a logistic regression analysis to examine the accurate influence path of personal characteristics on purchase preference.

Following prior research, this study carries out a contingency table analysis to 
display the frequency distribution of each consumer characteristic factor, and to confirm the significance of the interrelations between each characteristic factor and purchase preference. Table 2 reports the statistical results of the contingency table. Kendall's tau-b is used to show the aforementioned interrelations for ordinal variables, while the uncertainty coefficient is used for nominal variables. Consistent with the results in the literature ${ }^{4}$, through statistical tests, we note that most of the characteristics except for country are significant for the relationship with consumers' purchase preference for online and offline shopping $(p<0.01)$. Specifically, the variables for education $\left(\tau_{b}=0.01, \chi^{2}=23.16\right)$, work status $\left(\tau_{b}=0.14, \chi^{2}=66.05\right)$, and the experience of online shopping $\left(\tau_{b}=0.33, \chi^{2}=410.60\right)$ are positively correlated with online purchase preference, while age $\left(\tau_{b}=-0.16, \chi^{2}=108.86\right)$, and income $\left(\tau_{b}=\right.$ $\left.-0.06, \chi^{2}=23.89\right)$ are negative. In addition, the result shows that customers' purchase preference significantly differs across gender $(\beta=0.01, t=2.55)$, and it seems that females are more likely to make an in-shop purchase decision $\left(\tau_{b}=-0.09, \chi^{2}=26.05\right)$.

Table 2. Results of the contingency table analysis

\begin{tabular}{l|rrrrr}
\hline \multicolumn{1}{c|}{ Variables } & $\begin{array}{r}\text { Kendall's } \\
\text { tau-b }\end{array}$ & Chi-square & $\begin{array}{r}\text { Uncertainty } \\
\text { Coefficient }\end{array}$ & $t$-Value & Sig. \\
\hline Gender & -0.09 & 26.05 & 0.01 & 2.55 & 0.00 \\
Age & -0.16 & 108.86 & 0.03 & 5.33 & 0.00 \\
Education & 0.01 & 23.16 & 0.01 & 2.41 & 0.00 \\
Income & -0.06 & 23.89 & 0.01 & 2.44 & 0.00 \\
Country & -0.03 & 3.07 & 0.00 & 0.88 & 0.22 \\
Work status & 0.14 & 66.03 & 0.02 & 4.01 & 0.00 \\
Experience of online shopping & 0.33 & 410.60 & 0.11 & 10.40 & 0.00 \\
\hline
\end{tabular}

Note: The column variable in this table is " $1=$ purchase online" and " $0=$ purchase in-shop."

Given the significant interrelations between personal characteristics and purchase preference in the contingency table analysis, we apply two binary logistic regressions to obtain accurate measures of the effects of personal characteristics on purchase preference. In this study, it is assumed that consumer purchase preference for online or offline shopping is determined by the difference in total shopping costs between in-shop $C(0)$ and online $C(1)$. In other words, consumers prefer making an online purchase decision if $C(1)-C(0)+\epsilon>0$, where $\epsilon$ in the formula represents the error. Suppose that for each observation, the error term $\epsilon_{i}$ obeys a logistic distribution, thus the probability that consumer $i$ will make an online purchase $\left(p_{1 i}\right)$ and the probability that consumer $i$ will make a purchase offline $\left(p_{0 i}\right)$ can be expressed as the following two equations:

$$
\begin{aligned}
& p_{1 i}=\frac{1}{1+\exp \left(-\mathbf{X}_{\mathbf{i}} \mathbf{b}_{\mathbf{i}}\right)}=\frac{\exp \left(\mathbf{X}_{\mathbf{i}} \mathbf{b}_{\mathbf{i}}\right)}{1+\exp \left(\mathbf{X}_{\mathbf{i}} \mathbf{b}_{\mathbf{i}}\right)} \\
& p_{0 i}=\frac{1}{1+\exp \left(\mathbf{X}_{\mathbf{i}} \mathbf{b}_{\mathbf{i}}\right)}
\end{aligned}
$$

where $\mathbf{X}_{\mathbf{i}}$ and $\mathbf{b}_{\mathbf{i}}$ respectively represent the vectors for explanatory variables and unknown parameters for consumer $i$.

Zhang et al. ${ }^{44}$ have provided a complete solution of accurately measuring the effects. A naive approach assesses the effects of personal characteristics on online purchase preference without considering the effect of other aspects. We specify the following logit model, called Model-a, as a benchmark for further analyses. In this model, the dependent variable is the outcomes of customers purchase preference, which takes the value of 1 if consumer prefer to shop online, while it takes the value 
of 0 if they choose to shop in-store; subscript of $i$ indicates consumer $i ; p_{1}$ and $p_{2}$ represent the probabilities of purchase preferences for the Internet and local stores; $\mathbf{H}$ and $\mathbf{B}$ denotes the vectors for the variables of personal characteristics and their coefficients. Personal characteristics in this analysis include gender, income, age, education, work status, and the experience of online shopping. Among these personal characteristics, gender is a dummy variable, while others are ordinal variables as shown in Table 1.

$$
\ln \left(\frac{p_{1 i}}{p_{0 i}}\right)=\beta_{0}+\mathbf{H}_{\mathbf{i}} \mathbf{B} \quad \text { Model-a }
$$

Because there are strong correlations among these personal characteristics variables, which may result in the multicollinearity and cause some of their coefficients to be insignificant even if the stand-alone effect is significant ${ }^{44}$, this analysis estimates the models with one independent variable at a time. Although the use of ordinal variables cannot obtain an accurate assessment of the effects of personal characteristics on online purchase preference, the effect trend, if one exists, can be examined by this analysis. Table 3 reports the estimation results of these models (Model-a1 Model-a6). The results indicate that almost all of the personal characteristics have significant $(p<0.01)$ effects on the likelihood of online purchase, with the exception of education, based on this approach. As the table shows, female dummy, income level, and age are negatively related to online purchase preference, while the characteristics related to wired lifestyle and time constraint relate positively. In addition, income is shown to be negatively significant for the likelihood of purchasing online, which is in striking disagreement with previous studies ${ }^{5,6,27}$. This is partly because of the strong correlation between income and age. In most cases, younger customers shop more online but they have less income. Another possible explanation for this result is that with the continuous development of e-commerce, online shopping attracts more lower-income consumers because it enables consumers to save money?

Table 3. Parameter estimates of Model-a $(\mathrm{N}=2930)$

\begin{tabular}{|c|c|c|c|c|c|c|c|c|c|c|c|}
\hline \multicolumn{3}{|c|}{\begin{tabular}{c} 
Model-a1 \\
\cline { 2 - 3 } Gender
\end{tabular}} & \multicolumn{2}{|c|}{$\begin{array}{l}\text { Model-a2 } \\
\text { Income } \\
\end{array}$} & \multicolumn{2}{|c|}{$\begin{array}{c}\text { Model-a3 } \\
\text { Age }\end{array}$} & $\begin{array}{l}\text { Model-a4 } \\
\text { Education } \\
\end{array}$ & \multicolumn{2}{|c|}{$\begin{array}{l}\text { Model-a5 } \\
\text { Experience }\end{array}$} & \multicolumn{2}{|c|}{$\begin{array}{c}\text { Model-a6 } \\
\text { Work Status }\end{array}$} \\
\hline \multicolumn{12}{|c|}{ Coefficient Estimates } \\
\hline Gender (female) & $\begin{array}{r}-0.39 \\
(0.08)\end{array}$ & **** & & & & & & & & & \\
\hline Income & & & $\begin{array}{r}-0.08 \\
(0.03)\end{array}$ & **** & & & & & & & \\
\hline Age & & & & & $\begin{array}{r}-0.34 \\
(0.03)\end{array}$ & & & & & & \\
\hline Education & & & & & & & $\begin{array}{r}0.03 \\
(0.05)\end{array}$ & & & & \\
\hline Experience & & & & & & & & $\begin{array}{r}1.12 \\
(0.06)\end{array}$ & & & \\
\hline Work Status & & & & & & & & & & $\begin{array}{r}0.43 \\
(0.05)\end{array}$ & \\
\hline Intercept & $\begin{array}{r}0.73 \\
(0.05)\end{array}$ & **** & $\begin{array}{r}0.85 \\
(0.10)\end{array}$ & **** & $\begin{array}{r}1.63 \\
(0.12)\end{array}$ & **** & $\begin{array}{r}0.50 \\
(0.12)\end{array}$ & $\begin{array}{r}-1.73 \\
(0.13)\end{array}$ & **** & $\begin{array}{r}-0.45 \\
(0.13)\end{array}$ & **** \\
\hline Log-likelihood & -1909 & & -1917. & & -1872 & & -1922.40 & -1736 & 5.30 & -1890 & \\
\hline Likelihood Ratio & 25.96 & & 10.18 * & & 100.45 & & 0.27 & 372.4 & & 63.57 & \\
\hline Cox \& Snell R ${ }^{2}$ & 0.00 & & 0.003 & & 0.034 & & 0.000 & 0.11 & & 0.02 & \\
\hline Nagelkerke $\mathrm{R}^{2}$ & 0.01 & & 0.005 & & 0.046 & & 0.000 & 0.16 & & 0.02 & \\
\hline
\end{tabular}

Note: $* * * p<0.01, * * p<0.05, * p<0.1$. 
It is noteworthy that the explanatory variables in the naive choice approach are only individual characteristic factors. This is, of course, defective because many other characteristics such as the costs in money and time should influence purchase preference; these factors are necessarily included in the errors in Model-a, resulting in the very small Pseudo R-squared values (close to zero). Additionally, this study posits that personal characteristics moderate the effects of saving money and time on purchase preference. That is to say, the error contains factors that affect consumers' purchase outcomes and is highly correlated with personal characteristics, resulting in biased parameter estimates. To reduce the bias of parameter estimates and clarify the influence paths of personal characteristics on consumer online purchase preference, on the basis of Model-a, this study proceeds to Model-b. In Model-b, we introduced three factors: money-saved, time-saved, and delivery time, as extra explanatory variables that relate to the goals of saving money and time and add the respective interactions between those three explanatory variables and consumers' personal characteristics. Model-b is expressed as follows:

$$
\begin{gathered}
\ln \left(\frac{p_{1 i}}{p_{0 i}}\right)=\beta_{0}+\left(\beta_{1}+\mathbf{H}_{\mathbf{i}} \mathbf{B}_{\mathbf{1}}^{*}\right) \text { sav }_{\text {mon }_{i}}+\left(\beta_{2}+\mathbf{H}_{\mathbf{i}} \mathbf{B}_{2}^{*}\right) \operatorname{sav}_{\text {tim }} \\
+\left(\beta_{3}+\mathbf{H}_{\mathbf{i}} \mathbf{B}_{3}^{*}\right) \text { deli }_{i}+\mathbf{H}_{\mathbf{i}} \mathbf{B}
\end{gathered}
$$

where sav_mon and sav_tim, respectively indicate the values of saving money and time for online purchases compared with in-shop purchases, that is shown as the cost of offline shopping minus that of online shopping; and deli signifies the delivery time after an online purchase. The dependent variable and other independent variables are defined the same as in previously (i.e., Model-a). The fundamental statistics of the three control variables are as follows (see Table 4):

Table 4. Fundamental statistics of control variables

\begin{tabular}{l|rlrr}
\hline \multicolumn{1}{c|}{ Variables } & Mean & SD & Min & Max \\
\hline sav_mon & 4.70 & 3.25 & -3.90 & 15.90 \\
sav_tim & 1.89 & 1.50 & -3.60 & 6.90 \\
deli & 2.70 & 0.98 & 1.00 & 5.00 \\
\hline
\end{tabular}

Table 5 shows the parameter estimates of the moderation approach. Similar to Model-a, Model-b is also estimated with one individual characteristic variable at a time. In these models (Model-b1 Model-b6), sav_mon, sav_tim, and deli are the common variables. All the coefficients of money- and time-saved are positive, while the coefficients of the delivery time are negative. Since the coefficients in logit models cannot be directly compared, we checked the variances of the marginal effects of the three variables on the likelihood of online purchase to confirm the stability of the estimates. Small variances provide evidence for the validity of the data and the analyses. Stand deviation of the marginal effects of sav_mon, sav_tim, and deli are $0.002($ Mean $=1.50 \%), 0.002($ Mean $=2.14 \%)$, and 0.005 (Mean $=-8.59 \%)$, respectively. The analyses suggest that the preference for reducing shopping costs causes a consumer to be more likely to engage in online shopping.

For the direct effects of personal characteristics on online purchase preference, as shown in Table 5, only the coefficients of gender $(\beta=-3.93)$, age $(\beta=-2.47)$, and frequency of online shopping $(\beta=3.66)$ are significant, while other characteristics failed to emerge as significant factors for the direct effects on online purchase preference. In addition, although parameter estimates for the female dummy are negative and significant as expected, the marginal effect of it is limited $(3.11 \%)$. The 
results indicate that the characteristics of being young and having experience of online shopping have strong direct effects on online purchase preference. Therefore, hypotheses H1a, H3a, and H5a are supported, while $\mathrm{H} 2 \mathrm{a}, \mathrm{H} 4 \mathrm{a}$, and H6a are not. Although hypothesis $\mathrm{H} 1 \mathrm{a}$ is supported in this study, we noticed the gender difference in purchase preference is not obvious.

With respect to the moderating effects of personal characteristics, this paper focuses on the coefficients of the respective interactions between money-saved, time-saved, delivery time, and personal characteristics, which represent the change in slopes of the likelihood of online purchase on the three variables: sav_mon, sav_tim, and deli.

H1b predicts that the effects of saving money and time on online purchase preference are more pronounced for men than for women. That is to say, the variable for women negatively moderates the effects of money- and time-saved on online purchase. As expected, the interactions between being female and saving money ( $\beta=$ $-0.40)$ and time $(\beta=-0.72)$ are negatively significant $(p<0.05)$. Meanwhile, the interaction between being female and delivery time is revealed as positively significant $(\beta=4.22, p<0.01)$ in Model-b1 (see Table 5). These results indicate that men pay more attention to saving money and time than women when shopping online. Therefore, H1b is supported.

Table 5. Parameter estimates of Model-b (N=2930)

\begin{tabular}{|c|c|c|c|c|c|c|c|c|c|c|c|c|}
\hline \multirow{2}{*}{ Coefficient Estima } & \multicolumn{2}{|c|}{$\begin{array}{c}\text { Model-b1 } \\
\text { Gender }\end{array}$} & \multicolumn{2}{|c|}{$\frac{\text { Model-b2 }}{\text { Income }}$} & \multicolumn{2}{|c|}{$\frac{\text { Model-b3 }}{\text { Age }}$} & \multicolumn{2}{|c|}{$\begin{array}{l}\text { Model-b4 } \\
\text { Education }\end{array}$} & \multicolumn{2}{|c|}{$\begin{array}{c}\text { Model-b5 } \\
\text { Experience }\end{array}$} & \multicolumn{2}{|c|}{$\begin{array}{c}\text { Model-b6 } \\
\text { Work Status }\end{array}$} \\
\hline & & & & & & & & & & & & \\
\hline \multirow[t]{2}{*}{ sav_mon } & 1.31 & **** & 1.73 & *** & 1.19 & *** & 1.51 & $* * *$ & 1.31 & *** & 1.03 & $* * *$ \\
\hline & $(0.15)$ & & $(0.36)$ & & $(0.31)$ & & $(0.35)$ & & $(0.36)$ & & $(0.35)$ & \\
\hline \multirow[t]{2}{*}{$s a v \_m o n * \mathbf{M}$} & -0.40 & ** & -0.17 & ** & -0.17 & * & -0.25 & * & -0.09 & & 0.42 & $* * *$ \\
\hline & $(0.21)$ & & $(0.08)$ & & $(0.09)$ & & $(0.15)$ & & $(0.17)$ & & $(0.14)$ & \\
\hline \multirow[t]{2}{*}{ sav_tim } & 1.79 & **** & 1.21 & *** & 1.89 & **** & 2.27 & **** & 1.13 & ** & 1.01 & $*$ \\
\hline & $(0.23)$ & & $(0.57)$ & & $(0.49)$ & & $(0.56)$ & & $(0.53)$ & & $(0.54)$ & \\
\hline \multirow[t]{2}{*}{$s a v \_t i m * \mathbf{M}$} & -0.72 & *** & 0.23 & ** & -0.26 & * & -0.25 & & 0.25 & & 0.47 & *** \\
\hline & $(0.36)$ & & $(0.11)$ & & $(0.15)$ & & $(0.24)$ & & $(0.25)$ & & $(0.23)$ & \\
\hline \multirow[t]{2}{*}{ deli } & -9.92 & $* * *$ & -3.79 & ** & -6.46 & *** & -5.11 & *** & -7.14 & *** & -4.86 & **** \\
\hline & (2.68) & & (1.86) & & $(1.71)$ & & (1.59) & & (2.19) & & $(1.86)$ & \\
\hline \multirow[t]{2}{*}{$\operatorname{deli} * \mathbf{M}$} & 4.22 & **** & -1.24 & *** & 0.51 & ** & -0.53 & & 1.68 & *** & -0.95 & $* * *$ \\
\hline & (1.68) & & $(0.45)$ & & $(0.25)$ & & $(0.78)$ & & $(0.76)$ & & $(0.38)$ & \\
\hline \multirow[t]{2}{*}{ M } & -3.93 & *** & -0.85 & & -2.47 & $*$ & 2.62 & & 3.66 & ** & 1.16 & \\
\hline & $(2.05)$ & & (1.19) & & $(1.32)$ & & (2.13) & & (1.83) & & $(2.11)$ & \\
\hline \multirow{2}{*}{ Intercept } & 12.27 & ** & 16.89 & *** & 13.17 & *** & 6.54 & ** & 8.80 & *** & 9.19 & $*$ \\
\hline & $(6.05)$ & & $(4.79)$ & & $(4.63)$ & & $(3.24)$ & & (3.19) & & $(5.19)$ & \\
\hline Log-likelihood & \multicolumn{2}{|c|}{-1909.56} & \multicolumn{2}{|c|}{-1917.45} & \multicolumn{2}{|c|}{-1872.31} & \multicolumn{2}{|c|}{-1922.40} & \multicolumn{2}{|c|}{-1736.30} & \multicolumn{2}{|c|}{-1890.75} \\
\hline Likelihood Ratio & \multicolumn{2}{|c|}{$25.96^{* * *}$} & \multicolumn{2}{|c|}{$10.18^{* * *}$} & \multicolumn{2}{|c|}{$100.45^{\text {**** }}$} & \multicolumn{2}{|c|}{0.27} & \multicolumn{2}{|c|}{$372.48^{* * * *}$} & \multicolumn{2}{|c|}{$63.57^{* * *}$} \\
\hline Cox \& Snell R2 & \multicolumn{2}{|c|}{0.009} & \multicolumn{2}{|c|}{0.003} & \multicolumn{2}{|c|}{0.034} & 0.00 & & 0.11 & & 0.02 & \\
\hline Nagelkerke R2 & 0.01 & & 0.00 & & 0.04 & & 0.00 & & 0.16 & & 0.02 & \\
\hline Marginal Effect 1 & stimate & & & & & & & & & & & \\
\hline sav_mon & 1.49 & & 1.59 & & 1.59 & & 1.59 & & 1.15 & & 1.57 & \\
\hline$s a v \_t i m$ & 2.16 & & 2.07 & & 2.31 & & 2.32 & & 1.68 & & 2.31 & \\
\hline deli & -8.97 & & -8.34 & & -8.20 & & -8.30 & & -9.48 & & -8.23 & \\
\hline
\end{tabular}

$\mathrm{H} 2 \mathrm{~b}$ states that income relates negatively to saving money but relates positively to saving time in online shopping. To test $\mathrm{H} 2 \mathrm{~b}$, age is used as an ordinal variable. After calculating the coefficients of the interactions, the results in Model-b2 
demonstrate that income negatively moderates the effects of money-saved $(\beta=-0.17)$ and delivery $(\beta=-1.24)$ on online purchase intention but positively moderates the effect of time-saved $(\beta=0.23)$. Hence, $\mathrm{H} 2 \mathrm{~b}$ is supported.

$\mathrm{H} 3 \mathrm{~b}$ and $\mathrm{H} 4 \mathrm{~b}$ focus on the respective interactions between age, education, and the two online purchase goals. In Model-b3, the author finds that the interactions of age with money-saved $(\beta=-0.17)$ and time-saved $(\beta=-0.26)$ are negative, while the interaction between age and delivery time is positive $(\beta=0.51)$ as per the results in Model-b1. This finding shows that young consumers exhibit a greater tendency toward saving money and time in online shopping. However, there is only one significant $(p<0.1)$ interaction observed for education (with money-saved) in Model-b4, but the origin of this interaction is probably the correlation between education and income. This finding signifies that education largely failed to emerge as a significant moderator. Therefore, $\mathrm{H} 3 \mathrm{~b}$ is supported, while $\mathrm{H} 4 \mathrm{~b}$ is not supported.

$\mathrm{H} 5 \mathrm{~b}$ and $\mathrm{H} 6 \mathrm{~b}$ refer to the relationship between consumer lifestyle and attitude toward delivery time with regard to online shopping. As Table 5 shows, the interaction between the experience of online shopping and delivery time is positive $(\beta=1.68)$, while the interaction between work status and delivery is negative $(\beta=-0.95)$. Both of the two interactions are significant $(p<0.05)$. These results reflect that the negative effect of delivery time on online purchase intention is amplified by a busy work status but attenuated by the experience of online shopping, providing support for $\mathrm{H} 5 \mathrm{~b}$ and H6b. Table 6 represents the summary of the hypotheses testing.

Table 6. Results of hypotheses testing

\begin{tabular}{|c|c|c|c|c|c|c|c|}
\hline \multirow[b]{2}{*}{ Hypothesis } & \multirow[b]{2}{*}{ Factor } & \multicolumn{2}{|c|}{ Direct Effect (a) } & \multicolumn{4}{|c|}{ Moderating Effects (b) } \\
\hline & & Coef. & Result & $\begin{array}{c}\text { Coef. } \\
\text { (money-saved) }\end{array}$ & $\begin{array}{c}\text { Coef. } \\
\text { (time-saved) }\end{array}$ & $\begin{array}{c}\text { Coef. } \\
\text { (delivery time) }\end{array}$ & Result \\
\hline H1 & Gender $\rightarrow$ OPP & $-3.93 * *$ & Supported & $-0.40 * * *$ & $-0.72 * * *$ & $4.22 * * *$ & Supported \\
\hline $\mathrm{H} 2$ & Inc. $\rightarrow$ OPP & $-0.85 * *$ & Not supported & $-0.17 * * *$ & $0.23 * * *$ & $-1.24 * * *$ & Supported \\
\hline $\mathrm{H} 3$ & Age $\rightarrow$ OPP & $-2.47 * *$ & Supported & $-0.17 * * *$ & $-0.26 * * *$ & $0.51 * * *$ & Supported \\
\hline $\mathrm{H} 4$ & Edu. $\rightarrow$ OPP & $2.62 * *$ & Not supported & $-0.25 * * *$ & $-0.25 * * *$ & $-0.53 * * *$ & Not supported \\
\hline H6 & $\mathrm{WS} \rightarrow \mathrm{OPP}$ & $1.16 * *$ & Not supported & $0.42 * * *$ & $0.47 * * *$ & $-0.95 * * *$ & Supported \\
\hline
\end{tabular}

Note: OPP, online purchase preference; Inc, income; Edu, education level; OSE, online shopping experience; WS, work status; $* * * p<0.01, * * p<0.05, * p<0.1$

In addition, although the difference in consumer purchase preference across the countries does not fall within the research hypothesis of the present study, the results of contingency table analysis in the above article have indicated that the overall impact of nationality was not significant. Similar to this finding, the direct effects of nationality in both Model-a $\left(F_{(1,2928)}=1.19, p=0.28\right)$ and Model-b $\left(F_{(1,2919)}=0.61\right.$, $p=0.43)$ are also not significant. Furthermore, the differences in preference of saving money $\left(F_{(1,2919)}=1.54, p=0.22\right)$ and time $\left(F_{(1,2919)}=1.73, p=0.19\right)$ across different countries are not statistically obvious either. Nonetheless, one interesting observation is that with respect to the interaction between nationality and delivery time, we noticed that the decision-making of online purchase for Japanese consumer is largely dependent on the length of delivery delay $(\beta=-1.17, p<0.05)$. According to the depth interviews with Japanese consumers, which was designed and investigated by Manhattan Associates Japan, we noticed that this finding means they cannot endure the schedule delay of shipping in online shopping rather than overlong delivery time. From the perspective of cultural psychology, this is because compared with China and the US, the consumer in most online shopping can specify a delivery date and time in 
Japan, thus the delivery delay may be a huge loss for them.

\section{DISCUSSION AND CONCLUSION}

\subsection{Discussion}

Prior research has demonstrated that personal characteristics are critical factors to affect online purchase preference ${ }^{2,6}, 13$. However, little is known about the associated influence paths and mechanisms. This study posits that personal characteristics influence their behavioral intention by directly affecting the online purchase preference and moderating the preference effects from other factors. To examine the relationship between personal characteristics and shopping channel choice, and to clarify their influence paths, we performed a longitudinal survey and developed a moderation logit model to investigate the direct effects of personal characteristics on online purchase preference and the moderating effects of those socioeconomic factors on the influences from two online purchase goals: saving money and saving time. We conclude relatively general results through the usage of an online survey delivered in three of the world's largest online markets with different cultures and economic policies: the United States, Japan, and China. Through a brief comparison, Japanese consumers seem to place greater value on "time" than Chinese and American shoppers when they shopping online, but the difference is not obvious. The results show that only age and online experience have direct effects on online purchase preference.

Despite the existence of gender differences in online purchase preference in prior discussions, the direct effect of gender on the likelihood of purchasing online is shown to be limited in this study. By contrast, the moderating effects of gender on the influence of cost-saved and delivery time on online purchase preference are significant. This means that the influences of gender on purchase preference are primarily reflected in male consumers' greater tendency toward saving money and time, indicating that males are more likely to purchase online when online channel enables consumers to save money and saving time. One possible explanation is that males just want to purchase products that they need as cheaply and quickly as possible, while females have an innate love for the shopping context, which incites them to ignore the time they spend on shopping. Our findings are in line with prior research regarding gender difference in online purchase performance.

Although prior studies suggested that consumers who prefer online shopping mostly are high income ${ }^{6,27}$, our findings show some distinction; therefore, we cannot simply draw the positive correlation between income and online purchase preference. Instead, we find that consumers with a high income pay more attention to saving time, signifying that they are attracted to online shopping if it can help them more efficacy 9 . The rule behind this result might be the law of the diminishing marginal rate of substitution. This also leads lower-income consumers to exhibit a greater tendency toward purchasing online if they can save money by doing so.

This study provides evidence that youth demographic are more prone to making online purchases; this is because these consumers are relatively computer literate and are more comfortable with shopping online. Meanwhile, just like males, youth demographic also have a greater interest in online shopping due to its benefits of saving money and time. Furthermore, consumers with more online shopping experience have a higher probability of making an online purchase decision. This 
suggests that the number of online shoppers and the prevalence of online buying behavior will increase gradually along with the popularization of Internet usage. Meanwhile, we also note that having engaged in online shopping can attenuate consumer perceptions of risk related to delivery time.

Prior research pointed out that consumers with less discretionary time are more likely to purchase online ${ }^{27}$. However, in this study, online purchase preference is not found to be directly associated with work status, which is taken as the proxy of time constraints. Consistent with the results in Punj $^{9}$, we find that a consumer with a relatively busy work status gives more consideration to time spent on shopping than those who have more discretionary time. This is likely due to the high opportunity costs associated with lost time. Building on this finding, as a complement to previous studies, the conclusions in the literature that online shoppers tend to be more time-constrained is valid under the condition that online shopping provides the benefit of saving time.

The effects of education on consumers' online purchase preference are insignificant, both in the direct effect and the moderating effect. The finding is inconsistent with prior research. One possible explanation of the conflicting result is made by the heterogeneity in the time period. Prior research findings are mainly in the early stage of online shopping, during which consumers with better education usually play the role of early adopters of online purchasing ${ }^{45,46}$. However, this early leadership weakens with the popularity of shopping online.

\subsection{Implications for the academy}

This study contributes to the existing literature in two ways. First, despite the evidence suggesting that personal characteristics affect online purchase preference, the mechanism of these effects and their influence paths are unclear. Unlike prior research, which focused on the relationship of sample distribution between characteristics factors and preference outcomes ${ }^{6,27}$, we posit that personal characteristics affect preference outcomes as follows: the direct effects on purchase preference, and the indirect effects by moderating the purchase influences of other factors. That is, this study not only exam the direct effects of personal characteristics, such as gender, income, age, education, work status, and online experience on online purchase preference through rigor methods, but also investigate the moderating effects of these socioeconomic factors on the relationships between the two goals of saving money and time, and consumer purchase preference. This study fills the gap in the existing literature and finds that personal characteristics affect purchase outcomes mainly by moderating the preference effects of the two online purchase goals, rather than their direct effects.

\subsection{Implications for practice}

The managerial insights drawn from this study are that managers both in the online and offline channel have to clearly define their own target consumers and adjust their strategy for a different channel. Specifically, driven from the study findings, first, it is necessary that merchants should not only consider the kind of the target segments' characteristics but also take consumers' channel preference and attitude to money and time into account. Second, retailers should tailor their advertising strategies according to different population features. For instance, in the online channel, for male or lower-income consumers, managers can highlight the 
advantage on price, while for those time-starved consumers, it is better for shop managers to emphasize high efficiency in time. On the other hand, it may be more effective to advertise the shopping context and product assortment to females. Our findings suggest providing an appropriate rebate or coupon mechanism is helpful for online channel to improve the likelihood of consumer patronage because it can attract consumers' repeat purchase as well as increase the frequency of online shopping.

\section{LIMITATIONS}

This study suffers from two key limitations. Although we found that the effects of personal characteristics on purchase preference mainly reflect in the moderating effects rather than direct effects, this study only discussed how personal characteristics moderate preference effects of two online purchase goals: saving money and saving time. However, literature in consumer research also mentioned that perceived risk and hedonic orientation are also critical factors that influence online purchase preference ${ }^{7,47}$. In light of the importance of those two factors for consumer behavioral intention, we suggest that future research take into consideration the moderating effects of personal characteristics on perceived risk and hedonic orientation in online shopping. Secondly, this study focuses on only one product (i.e., clothing) to investigate the relationship between personal characteristics and patronage preferences for the online and offline stores but gives no consideration to the influence of product attributes. Therefore, it is also necessary to discuss the differences in the relationship between personal characteristics and patronage preference across different product classes in future research.

\section{ACKNOWLEDGMENT}

We would like to thank editor and anonymous reviewers for their thoughtful reviews and constructive suggestions during the review process. Secondly, we thank Prof. Arch G. Woodside for his insightful comments about analytical and predictive validity on early versions of this paper. Finally, we are grateful to Prof. Hideki Murakami, who is no longer with us, for his invaluable guidance and helpful suggestions, which have significantly improved the quality of data measurement and modelling of this study. Without his inspiration, the article could not have been written. We know he will be happy and have peace wherever he is now.

\section{REFERENCES}

[1] T. Perea Monsuwe, B. G. Dellaert, and K. De Ruyter, What drives consumers to shop online? A literature review. International Journal of Service Industry Management, 15(1), 102-121, 2004. https://doi.org/10.1108/09564230410523358.

[2] Statista, Number of digital shoppers in the United States from 2010 to 2018. Retrieved on June 16, 2016, from http://www.statista.com/statistics/183755/number-of-us-internet-shoppers-since$2009 /$.

[3] China Electronic Commerce Research Center, Data Monitoring of China's E-commerce Market in 2017. Retrieved on September 19, 2017, from http://www.100ec.cn/zt/17jcbg1/.

[4] J. N. Sheth, An integrative theory of patronage preference and behavior. College of Commerce and Business Patronage Behavior and Retail Management, 
North-Holland, New York, 1983.

[5] B. Hernandez, J. Jimenez, and M. J. Martin, Age, gender and income: do they really moderate online shopping behaviour? Online Information Review, 35(1), 113-133, 2011. https://doi.org/10.1108/14684521111113614.

[6] A. M. Levin, I. P. Levin, and J. A. Weller, A multi-attribute analysis of preferences for online and offline shopping: Differences across products, consumers, and shopping stages. Journal of Electronic Commerce Research, 6(4), 281-290, 2005.

[7] G. L. Lohse, S. Bellman, and E. J. Johnson, Consumer buying behavior on the internet: Findings from panel data. Journal of Interactive Marketing, 14(1), $15-29$, 2000. https://doi.org/10.1002/(SICI)1520-6653(200024)14:1<15::AID-DIR2>3.0.CO;2 $-\mathrm{C}$.

[8] W. R. Swinyard, and S. M. Smith, Why people (don't) shop online: A lifestyle study of the internet consumer. Psychology \& Marketing, 20(7), 567-597, 2003. https://doi.org/10.1002/mar.10087.

[9] S. M. Forsythe, and B. Shi, Consumer patronage and risk perceptions in internet shopping. Journal of Business Research, 56(11), 867-975, 2003. https://doi.org/10.1016/S0148-2963(01)00273-9.

[10] D. J. Kim, D. L. Ferrin, and H. R. Rao, A trust-based consumer decision-making model in electronic commerce: The role of trust, perceived risk, and their antecedents. Decision Support Systems, 44(2), 544-564, 2008. https://doi.org/10.1016/j.dss.2007.07.001.

[11] G. Punj, Income effects on relative importance of two online purchase goals: Saving time versus saving money? Journal of Business Research, 65(5), 634-640, 2012. https://doi.org/10.1016/j.jbusres.20 11.03.003.

[12] T. Hansen, and J. M. Jensen, Shopping orientation and online clothing purchases: The role of gender and purchase situation. European Journal of Marketing, 43(9/10), 1154-1170, 2009. https://doi.org/10.1108/03090560910976410.

[13] P. A. Pavlou, and M. Fygenson, Understanding and predicting electronic commerce adoption: An extension of the theory of planned behavior. MIS Quarterly, 30(1), 115-143, 2006.

[14] A. J. Rohm, and V. Swaminathan, A typology of online shoppers based on shopping motivations. Journal of Business Research, 57(7), 748-757, 2004. https://doi.org/10.1016/S0148-2963(02)00351-X.

[15] T. Girard, and P. Dion, Validating the search, experience, and credence product classification framework. Journal of Business Research, 63(9), 1079-1087, 2010. https://doi.org/10.1016/j.jbusres.2008.12.011.

[16] J. Cohen, P. Cohen, S. G. West, and L. S. Aiken, Applied multiple regression/correlation analysis for the behavioral sciences. Routledge, 2003.

[17] R. M. Baron, and D. A. Kenny, The moderator - mediator variable distinction in social psychological research: Conceptual, strategic, and statistical considerations. Journal of Personality and Social Psychology, 51(6), 1173-1182, 1986.

[18] E. Garbarino, and M. Strahilevitz, Gender differences in the perceived risk of buying online and the effects of receiving a site recommendation. Journal of $\begin{array}{llll}\text { Business } & \text { Research, 767(7), }\end{array}$ https://doi.org/10.1016/S0148-2963(02)00363-6.

[19] S. Rodgers, and M. A. Harris, Gender and e-commerce: An exploratory study. Journal of Advertising Research, 43(3), 322-329, 2003. https://doi.org/10.2501/JAR-43-3-322-329. 
[20] C. V. Slyke, Christie L. Comunale, and F. Belanger, Gender differences in perceptions of web-based shopping. Communications of the ACM, 45(7), 82-86, 2002. https://doi.org/10.1145/545151.545155.

[21] S. Caswell, Women enjoy e-shopping less than men. E-commerce Times, 11, 2000.

[22] C. Yang, and C. C. Wu, Gender differences in online shoppers' decision-making styles. e-Business and Telecommunication Networks, 14, 99-106, 2006. https://doi.org/10.1007/1-4020-4761-4_6.

[23] C. Comber, A. Colley, D. J. Hargreaves, and L. Dorn, The effects of age, gender and computer experience upon computer attitudes. Educational Research, 39(2), 123-133, 1997. https://doi.org/10.1080/ 0013188970390201.

[24] Z. Li, and L. Huang, How consumer characteristics moderate time effects on online purchase preference: An empirical analysis. Asia Marketing Journal, 16(3), 1-22, 2014. https://doi.org/10.15830/ amj.2014.16.3.1.

[25] S. Bae, and T. Lee, Gender differences in consumers' perception of online consumer reviews. Electronic Commerce Research, 11(2), 201-214, 2011. https://doi.org/10.1007/s10660-010-9072-y.

[26] R. Sebastianelli, N. Tamimi, and M. Rajan, Perceived quality of online shopping: Does gender make a difference? Journal of Internet Commerce, 7(4), 445-469, 2008. https://doi.org/10.1080/15332 860802507164 .

[27] H. E. Bouis, The effect of income on demand for food in poor countries: Are our food consumption databases giving us reliable estimates? Journal of $\begin{array}{llll}\text { Development } \quad \text { Economics, } & \text { 44(1), } & 1994.226, & \end{array}$ https://doi.org/10.1016/0304-3878(94)00012-3.

[28] E. M. Okada, and S. J. Hoch, Spending time versus spending money. Journal of Consumer Research, 31(2), 313-323, 2004. https://doi.org/ 10.1086/422110.

[29] S. Bellman, G. L. Lohse, and E. J. Johnson, Predictors of online buying behavior. Communications of the ACM, 42(12), 32-38, 1999.

[30] A. Goolsbee, and P. J. Klenow, Valuing consumer products by the time spent using them: An application to the internet, technical report. National Bureau of Economic Research, 2006.

[31] S.-Z. Chiou-Wei, and J. J. Inman, Do shoppers like electronic coupons? A panel data analysis. Journal of Retailing, 84(3), 297-307, 2008. https://doi.org/10.1016/j.jretai.2008.07.003.

[32] H.-P. Lu, C.-L. Hsu, and H.-Y. Hsu, An empirical study of the effect of perceived risk upon intention to use online applications. Information Management \& Computer Security, 13(2), 106-120, 2005. https://doi.org/10.1108/09685220510589299.

[33] Y. Wan, M. Nakayama, and N. Sutcliffe, The impact of age and shopping experiences on the classification of search, experience, and credence goods in online shopping. Information Systems and e-Business Management, 10(1), 135-148, 2012. https://doi.org/ 10.1007/s10257-010-0156-y.

[34] W. A. Henry, The effect of information-processing ability on processing accuracy. Journal of Consumer Research, 7(1), 42-48, 1980.

[35] G. T. M. Hult, D. J. Ketchen, and S. F. Slater, Information processing, knowledge development, and strategic supply chain performance. Academy of Management Journal, 47(2), 241-253, 2004. https://doi.org/10.5465/20159575.

[36] S. E. Beatty, and S. M. Smith, External search effort: An investigation across several product categories. Journal of Consumer Research, 14(1), 83-95, 1987. https://doi.org/10.1086/209095.

[37] J. E. Russo, G. Krieser, and S. Miyashita, An effective display of unit price 
information. Journal of Marketing, 39(2), 11-19, 1975.

[38] H. Li, C. Kuo, and M. G. Rusell, The impact of perceived channel utilities, shopping orientations, and demographics on the consumer's online buying behavior. Journal of Computer-Mediated Communication, 5(2), 1999. https://doi.org/10.1111/j.1083-6101.1999. tb00336.x.

[39] A. M. Susskind, Electronic commerce and world wide web apprehensiveness: An examination of consumers' perceptions of the world wide web. Journal of Computer-Mediated Communication, 2004. https://doi.org/10.1111/j.1083-6101.2004.tb00287.x.

[40] W. W. Moe, and P. S. Fader, Dynamic conversion behavior at e-commerce sites. Management Science, 50(3), 326-335, 2004. https://doi.org/10.1287/mnsc.1040.0153.

[41] M. Brown, N. Pope, and K. Voges, Buying or browsing? An exploration of shopping orientations and online purchase intention. European Journal of Marketing, 37(11/12), 1666-1684, 2003.

[42] L. Zhou, L. Dai, and D. Zhang, Online shopping acceptance model-a critical survey of consumer factors in online shopping. Journal of Electronic Commerce Research, 8(1), 41-62, 2007. https://doi.org/10.1108/03090560310495401.

[43] H. Nysveen, and P. E. Pedersen, An exploratory study of customers' perception of company web sites offering various interactive applications: Moderating effects of customers' internet experience. Decision Support Systems, 37(1), 137-150, 2004. https://doi.org/10.1016/S0167-9236(02)00212-9.

[44] F. Leclerc, B. H. Schmitt, and L. Dube, Waiting time and decision making: Is time like money? Journal of Consumer Research, 22(1), 110-119, 1995.

[45] J.-C. Huang, T. C. Haab, and J. C. Whitehead, Willingness to pay for quality improvements: Should revealed and stated preference data be combined? Journal of Environmental Economics and Management, 34(3), 240-255, 1997. https://doi.org/10.1006/jeem.1997.1013.

[46] J. Zhang, M. Wedel, and R. Pieters, Sales effects of attention to feature advertisements: A Bayesian mediation analysis. Journal of Marketing Research, 46(5), 669-681, 2009.

[47] M. D. Dickerson, and J. W. Gentry, Characteristics of adopters and non-adopters of home computers. Journal of Consumer Research, 10(2), 225-235, 1983.

[48] C. S. Yiu, K. Grant, and D. Edgar, Factors affecting the adoption of internet banking in Hong Kong-Implications for the banking sector. International Journal of Information Management, 27(5), 336-351, 2007. https://doi.org/10.1016/j.ijinfomgt.2007.03.002.

[49] D. Scarpi, Work and fun on the internet: The effects of utilitarianism and hedonism online. Journal of Interactive Marketing, 26(1), 53-67, 2012. https://doi.org/10.1016/j.intmar.2011.08.001. 


\section{APPENDIX A.}

Questionnaires of Online survey

1. Demographics

$1)$. What is your nationality?

- A. China; B. the United States; C. Japan; D. Others

2). What is your gender?

- A. Male; B. Female

$3)$. How old are you?

- A. Under 20; B. 20 - 29; C. 30 - 39; D. 40 - 49; E. Over 50

4). What's your educational background at present?

- A. Under high school; B. College; C. Graduate

$5)$. What's your level of annual income at present?

- A. Less than $\$ 5,000$; B. $\$ 5,000$ to $\$ 15,000 ;$ C. $\$ 15,000$ to $\$ 30,000$;

D. $\$ 30,000$ to $\$ 50,000$; E. $\$ 50,000$ to $\$ 80,000$; F. More than $\$ 80,000$

2. Lifestyle

1). How many days do you work per week?

- A. Less than 3 days; B. 3 days to 4 days; C. 5 days or above

2). How many times do you shop online per month?

- A. Less than 3 times; B. 3 times to 9 times; C. 10 times or above

\section{Choice}

Assume that you decided to buy an item. The total spending and total shopping time are $S_{1}$ and $T_{1}$ for purchasing from a local store, while they are $S_{2}$ and $T_{2}$ for purchasing from the online. In addition, the delivery time for purchasing online is $D_{2}$. Thus, which purchase pattern will you choose?

- A. Purchase from online B. Purchase from local store; C. Either

Note: The item is randomly given from a category of clothing; The costs of money and time in the Online and physical stores are given by random stated preference data, whose ranges are based on the related information in Amazon.com. 
International Journal of Electronic Commerce Studies 